\title{
Long-term survival in patients hospitalized for chronic obstructive pulmonary disease: a prospective observational study in the Nordic countries
}

\author{
This article was published in the following Dove Press journal: \\ International Journal of COPD \\ 12 September 2012 \\ Number of times this article has been viewed
}

\section{Gunnar Gudmundsson ${ }^{1,2}$ \\ Charlotte Suppli Ulrik ${ }^{3}$ \\ Thorarinn Gislason ${ }^{1,2}$ \\ Eva Lindberg ${ }^{4}$ \\ Eva Brøndum ${ }^{3}$ \\ Per Bakke ${ }^{5}$ \\ Christer Janson ${ }^{3}$}

'Department of Respiratory Medicine, Allergy and Sleep, National University Hospital, Reykjavik, Iceland; ${ }^{2}$ Faculty of Medicine, University of Iceland, Reykjavik, Iceland; ${ }^{3}$ Department of Respiratory Diseases, Hvidovre Hospital, University of Copenhagen, Copenhagen, Denmark; ${ }^{4}$ Department of Medical Sciences: Respiratory Medicine and Allergology, Uppsala University, Uppsala, Sweden; ${ }^{5}$ Haukeland University Hospital, Bergen, Norway
Correspondence: Charlotte Suppli Ulrik Virum Overdrevsvej 13,

DK-2830 Virum, Denmark

Tel +453862 6089

Fax +45 4583 633।

Email csulrik@dadlnet.dk

\begin{abstract}
Background and aim: Mortality rate is high in patients with chronic obstructive pulmonary disease (COPD). Our aim was to investigate long-term mortality and associated risk factors in COPD patients previously hospitalized for a COPD exacerbation.

Methods: A total of 256 patients from the Nordic countries were followed for $8.7 \pm 0.4$ years after the index hospitalization in 2000-2001. Prior to discharge, the St George's Respiratory Questionnaire was administered and data on therapy and comorbidities were obtained. Information on long-term mortality was obtained from national registries in each of the Nordic countries.
\end{abstract}

Results: In total, 202 patients (79\%) died during the follow up period, whereas 54 (21\%) were still alive. Primary cause of death was respiratory $(n=116)$, cardiovascular $(n=43)$, malignancy $(\mathrm{n}=28)$, other $(\mathrm{n}=10)$, or unknown $(\mathrm{n}=5)$. Mortality was related to older age, with a hazard risk ratio (HRR) of 1.75 per 10 years, lower forced expiratory volume in 1 second $\left(\mathrm{FEV}_{1}\right)$ (HRR 0.80), body mass index (BMI) $<20 \mathrm{~kg} / \mathrm{m}^{2}$ (HRR 3.21), and diabetes (HRR 3.02). Older age, lower BMI, and diabetes were related to both respiratory and cardiovascular mortality. An association was also found between lower $\mathrm{FEV}_{1}$ and respiratory mortality, whereas mortality was not significantly associated with therapy, anxiety, or depression.

Conclusion: Almost four out of five patients died within 9 years following an admission for COPD exacerbation. Increased mortality was associated with older age, lower lung function, low BMI, and diabetes, and these factors should be taken into account when making clinical decisions about patients who have been admitted to hospital for a COPD exacerbation.

Keywords: acute exacerbation, long-term mortality, co-morbidity, diabetes, lung function

\section{Introduction}

More advanced chronic obstructive pulmonary disease (COPD) is associated with recurrent exacerbations characterized by acute worsening of dyspnea, cough, and sputum production. ${ }^{1}$ Previous studies on mortality following hospitalization for an acute exacerbation of COPD (AECOPD) have shown a short-term mortality of up to $49 \% .^{2-4}$ The 3-year mortality after hospitalization for AECOPD has been reported to be up to $54 \% .^{5-7}$ A large study of outpatients suffering from COPD observed a 3 -year mortality of only $14.3 \%{ }^{8}$ Studies on patients followed after AECOPD found the 5-year mortality to be $73 \%-76 \% .^{9,10}$

Patients previously hospitalized for AECOPD represent a high-risk group, and identification of, hopefully modifiable, risk factors are therefore of utmost importance. 
Previous studies of this high-risk group of patients have identified increasing age, signs of respiratory failure, ${ }^{2}$ maintenance use of systemic steroids, ${ }^{2}$ impaired health status, single status, depression, comorbidity, and a history of previous hospitalizations for AECOPD as risk factors for mortality. ${ }^{11}$ The frequency of exacerbations has also been shown to have an impact on overall mortality after a follow-up period of 5 years. ${ }^{12}$ Based on a 2-year follow-up study of our COPD cohort, we have previously reported that patients with diabetes hospitalized for AECOPD had an increased mortality rate compared to nondiabetic patients with AECOPD. To our knowledge, this was the first study to show this relationship. ${ }^{4}$ Our previous study also showed that cardiovascular comorbidity and a high depression score increased the risk of mortality in patients with an impaired health status. ${ }^{4}$ In order to expand further on these observations, and add to our present knowledge, we considered it important to evaluate long-term mortality in our cohort of Nordic COPD patients.

The primary aim of the present study has been to investigate long-term mortality ( $>8$ years) in COPD patients previously hospitalized for an acute exacerbation of the disease, and secondly to identify risk factors for mortality.

\section{Methods}

In earlier publications, we have described in detail our prospective Nordic study of patients hospitalized for an AECOPD at five university hospitals in each of the Nordic countries. ${ }^{4,13,14}$ The departments included were: the Department of Respiratory Medicine and Allergology, Akademiska Sjukhuset, Uppsala, Sweden; the Department of Respiratory Medicine, Vifilstadir University Hospital, Gardabaer, Iceland; and the Department of Respiratory Medicine, Hvidovre Hospital, Copenhagen, Denmark. Approval from the ethics committee was obtained at each center. Briefly, patients were enrolled consecutively during an admission for a COPD exacerbation in 2000-2001, and COPD was defined according to the Global Initiative for Chronic Obstructive Pulmonary Disease (GOLD) guidelines. ${ }^{1}$ The principal investigator at each center reviewed all case records and written informed consent was obtained from all participating subjects.

The case record forms used at all centers included the following information: smoking status, family status, height, body weight, spirometry results including predicted value for forced expiratory volume in 1 second $\left(\mathrm{FEV}_{1}\right),{ }^{15} \mathrm{COPD}$ severity according to GOLD, ${ }^{1}$ health status (assessed by $\mathrm{St}$ George's Respiratory Questionnaire $[\mathrm{SGRQ}]^{16}$ ), anxiety and depression (assessed by the Hospital Anxiety and Depression Scale $^{17}$ ), comorbidities (including diabetes and cardiovascular disease), and medication for COPD (including long-term oxygen therapy). The last patient was enrolled in the present study prior to the marketing of tiotropium in the Nordic countries.

Approximately 9 years after the index hospitalization for COPD, information regarding vital status and causes of death was obtained from the national registries in each country. The primary cause of death was divided into the following categories: (1) respiratory causes including: exacerbation of COPD (ICD-10 DJ440/DJ441), respiratory failure (DJ96x), and lower respiratory tract infection (DJ12 to DJ18), (2) cardiovascular causes, including myocardial infarction (DI21), left ventricular failure (DI50), stroke (DI61 to DI63), and pulmonary embolism (DI26), (3) Malignancy, including lung cancer (DC34), and breast cancer (DC50), and (4) Other causes, including septic shock (DR57) and aspiration (DJ69).

\section{Statistics}

Analyses were carried out using Stata software (v 9.0; Stata Corporation, College Station, TX). The chi-square test and the unpaired $t$-test were used when comparing baseline characteristics of patients that had died and survived, respectively, during the study period. The relationship between survival time and patient characteristics was determined with Kaplan-Meier survival analysis and Cox regression. Multivariate analyses were carried out with the Cox model. The analyzed independent variables were chosen based on statistical significance in the bivariate analyses $(P<0.10)$ and on clinical relevance. Age, $\mathrm{FEV}_{1}$, and health status were entered as continuous variables, while sex, smoking status, comorbidity, and treatment were entered as categorical variables. Variables related to pharmacological treatment were entered into the model as described previously. ${ }^{4}$ Interaction analyses were done looking at the possible differences in independent risk factors for mortality in relation to GOLD stage, sex, and smoking status. A $P$-value of $<0.05$ was considered statistically significant.

\section{Results}

A total of 256 patients (110 women and 146 men) from Copenhagen $(\mathrm{n}=88)$, Reykjavik $\mathrm{n}=81$, and Uppsala $(\mathrm{n}=87)$ previously hospitalized for a COPD exacerbation in the years 2000-2001 were included in the analyses. Mean follow-up for the patient cohort time was $8.7 \pm 0.4$ years. At the end of the follow-up, 202 patients (79\%) had died, whereas $54(21 \%)$ patients were still alive. Primary cause 
of death was respiratory $(n=116)$, cardiovascular $(n=43)$, malignancy $(n=28)$, other $(n=10)$, while no information was available for five patients (Figure 1). The baseline characteristics of the patients who were either dead or alive at the time of follow-up are presented in Table 1. In general, patients who died during follow-up were older and had lower BMI. They also had lower lung function and higher GOLD stages at the time of discharge from hospital in 2000-2001. There were no other significant associations including treatment, anxiety, and depression. As expected, the highest prevalence of diabetes (24\%) was found in the obese group (BMI $>30 \mathrm{~kg} / \mathrm{m}^{2}$ ), followed by the overweight group (BMI $\left.25-30 \mathrm{~kg} / \mathrm{m}^{2}\right)(13 \%)$. The prevalence of diabetes in those with a $\mathrm{BMI}<25 \mathrm{~kg} / \mathrm{m}^{2}$ was $6 \%$.

In the multivariable analyses (Table 2), mortality was related to older age, lower lung function, lower BMI, and diabetes. Older age, lower BMI, and diabetes were related to both respiratory and cardiovascular mortality. Respiratory mortality was related to lower lung function. There was no association between mortality and treatment, anxiety, or depression (data not shown).

A significant relationship between GOLD stages and survival was found (Figure 2). The proportion of respiratory death increased and the proportion of cardiovascular deaths decreased with increasing COPD severity (Figure 3 ). There were no significant differences in the relationship between determinants for mortality between the different GOLD stages (data not shown).

Women were more likely than men to have cancer as recorded cause of death (Figure 4). Diabetes was more strongly related to all-cause mortality in men than in women (odds ratio [OR], 4.77; 95\% confidence interval $[\mathrm{CI}]: 1.82-12.5$, versus OR, $1.79 ; 95 \%$

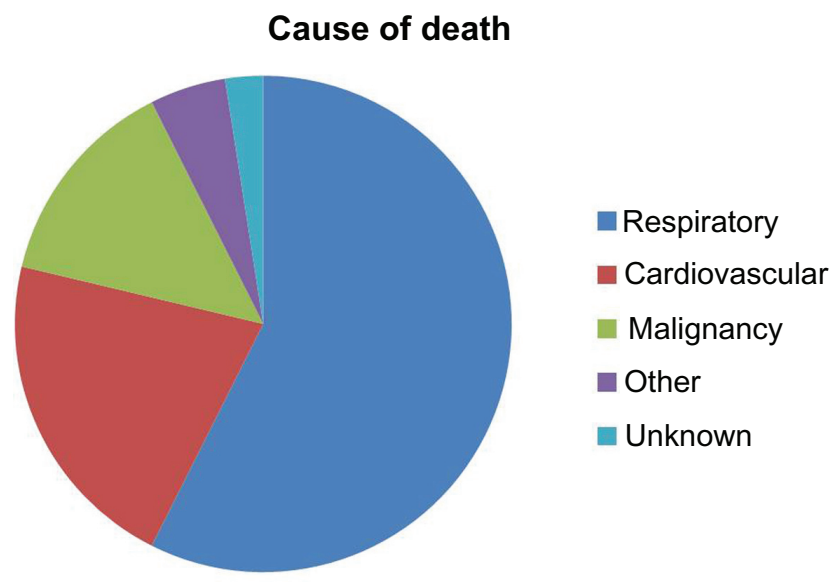

Figure I Distribution of causes of death in patients previously admitted to hospital for an acute exacerbation in chronic obstructive pulmonary disease.
Table I Baseline characteristics for patients $(n=256)$ with a previous hospital admission for COPD according to vital status at the time of follow-up ( $n, \%$ or mean \pm SD)

\begin{tabular}{|c|c|c|c|}
\hline & $\begin{array}{l}\text { Alive } \\
n=54\end{array}$ & $\begin{array}{l}\text { Dead } \\
n=202\end{array}$ & $P$-value* \\
\hline Men (\%) & $20(37)$ & $89(44)$ & 0.32 \\
\hline Age (years) & $63 \pm 10$ & $71 \pm 9$ & $<0.000 I^{*}$ \\
\hline Current smoker (\%) & $18(33)$ & $46(23)$ & 0.12 \\
\hline Pack years & $36 \pm 21$ & $41 \pm 24$ & 0.19 \\
\hline FEV,$\%$ pred & $47 \pm 19$ & $36 \pm 18$ & $0.000 I^{*}$ \\
\hline GOLD stages (\%) & & & $<0.000 I^{*}$ \\
\hline Stage I-2 & $25(47)$ & $10(18)$ & \\
\hline Stage 3 & $16(29)$ & $61(30)$ & \\
\hline Stage 4 & $13(24)$ & $105(52)$ & \\
\hline BMI & $26 \pm 6$ & $24 \pm 5$ & $0.004 *$ \\
\hline BMI groups (\%) & & & 0.02 \\
\hline$<20$ & $5(9)$ & $42(2 \mathrm{I})$ & \\
\hline $20-25$ & $18(33)$ & $91(45)$ & \\
\hline $25-30$ & $23(42)$ & $44(22)$ & \\
\hline$>30$ & $9(16)$ & $22(\mathrm{II})$ & \\
\hline College education (\%) & $14(26)$ & $48(24)$ & 0.83 \\
\hline Living alone (\%) & $29(54)$ & $125(62)$ & 0.28 \\
\hline Cardiovascular disease (\%) & $20(37)$ & $97(48)$ & 0.15 \\
\hline Diabetes (\%) & $4(7.4)$ & $22(11)$ & 0.45 \\
\hline Anxiety (\%) & $7(13)$ & $42(2 I)$ & 0.21 \\
\hline Depression (\%) & $5(10)$ & (9) & 0.80 \\
\hline \multicolumn{4}{|l|}{ SGRQ } \\
\hline Total & $51 \pm 18$ & $55 \pm 17$ & 0.10 \\
\hline Symptom & $60 \pm 18$ & $63 \pm 21$ & 0.44 \\
\hline Activity & $59 \pm 25$ & $66 \pm 21$ & $0.046 *$ \\
\hline Impact & $41 \pm 19$ & $44 \pm 18$ & 0.31 \\
\hline LABA and/or ICS (\%) & & & 0.23 \\
\hline None & $7(13)$ & $44(22)$ & \\
\hline LABA alone & $6(11)$ & $22(11)$ & \\
\hline ICS alone & $12(22)$ & $56(28)$ & \\
\hline LABA and ICS & $29(53)$ & $77(38)$ & \\
\hline Long term oxygen treatment (\%) & $7(13)$ & $50(25)$ & 0.06 \\
\hline
\end{tabular}

Note: *Statistically significant.

Abbreviations: $\mathrm{FEV}_{1}$, forced expiratory volume in I second; GOLD, Global Initiative for Chronic Obstructive Lung Disease; BMI, body mass index; SGRQ, St George's Respiratory Questionnaire; LABA, long-acting $\beta_{2}$-agonists; ICS, inhaled corticosteroids.

CI: $0.82-3.89 ; P=0.03)$. No interaction was found between risk factors for mortality and smoking.

\section{Discussion}

Nine years after hospitalization for an AECOPD, the majority (79\%) of the patients had died, primarily from respiratory $(57 \%)$ and cardiovascular $(21 \%)$ causes. Higher age, lower $\mathrm{BMI}$, lower $\mathrm{FEV}_{1}$, and diabetes were the major risk factors for mortality.

Information is available on long-term mortality in patients with COPD after hospitalization for AECOPD from other studies. A study from Italy followed 288 patients, mean $\mathrm{FEV}_{1}$ $46 \%$, for 6 years after hospitalization for COPD, and observed a $19 \%$ mortality rate. ${ }^{18}$ A study on patients with AECOPD 
Table 2 Risk factors for death during follow-up in patients with a previous hospital admission for COPD, according to all-cause mortality, respiratory mortality, and cardiovascular mortality, respectively

\begin{tabular}{llll}
\hline & $\begin{array}{l}\text { All causes } \\
\text { HRR }(95 \% \text { CI) }\end{array}$ & Respiratory death & Cardiovascular death \\
\hline Women & $0.77(0.54-1.10)$ & $0.66(0.41-1.07)$ & $0.52(0.18-1.48)$ \\
Age I0 years & $1.75(1.40-2.19)^{*}$ & $2.03(1.47-2.82)^{*}$ & $3.07(1.80-5.25)^{*}$ \\
Current smoker & $1.18(0.78-1.79)$ & $1.57(0.83-2.82)$ & $0.94(0.37-2.42)$ \\
FEV $\%$ predicted & $0.81(0.71-0.91)^{*}$ & $0.63(0.51-0.78)^{*}$ & $0.90(0.7 I-1.14)$ \\
BMI groups & & & \\
$\quad<20$ & $3.21(1.83-5.60)^{*}$ & $3.99(1.77-8.99)^{*}$ & $7.82(1.66-36.8)^{*}$ \\
$20-25$ & $1.42(0.89-2.28)$ & $1.57(0.76-3.27$ & $1.80(0.58-5.63)$ \\
$25-30$ & 1 & 1 & 1 \\
$>30$ & $1.82(0.95-3.47)$ & $1.68(0.57-4.97)$ & $3.28(0.87-12.4)$ \\
Cardiovacular disease & $1.24(0.85-1.81)$ & $1.20(0.69-2.09)$ & $1.98(0.69-5.72)$ \\
Diabetes & $3.02(1.69-5.40)^{*}$ & $4.92(1.51-16.0)^{*}$ & $5.48(2.03-14.8)^{*}$ \\
SGRQ total score & $1.04(0.99-1.09)$ & $1.00(0.93-1.08)$ & $1.02(0.92-1.13)$ \\
\hline
\end{tabular}

Note: $* P<0.05$.

Abbreviations: HRR, hazard risk ratio; FEV , forced expiratory volume in I second; BMI, body mass index; SGRQ, St George's Respiratory Questionnaire.

severe enough to be treated in intensive care unit found the 5-year mortality to be $76 \% .{ }^{9}$ A Danish study found overall 5 -year mortality to be $73 \%$ after treatment for AECOPD and it was higher in those that had been hospitalized. ${ }^{19}$ A population-based study of 20,571 participants with a 10-year median follow-up showed that hospitalization for COPD increased the subsequent mortality risk. ${ }^{20}$

Multiple studies on long-term mortality in nonhospitalized patients are available. A study from Japan that followed a cohort of patients with COPD found that 5-year mortality was $27 \%$. Of the 183 patients in the study, 42 patients (23\%) had $\mathrm{FEV}_{1}$ greater than $50 \%$ of the predicted value, 59 patients (32\%) had $\mathrm{FEV}_{1} 35 \%$ to $49 \%$ of the predicted value, and 82 patients (45\%) had $\mathrm{FEV}_{1}$ less than $35 \%$ of the predicted value. ${ }^{21}$ One study followed a COPD cohort in a populationbased study for 20 years and found overall mortality of $54 \%$ and $81 \%$ for those with severe and very severe COPD at entry. ${ }^{22}$ In a follow-up over 22 years of a large general population cohort of 923 cases of COPD found an overall

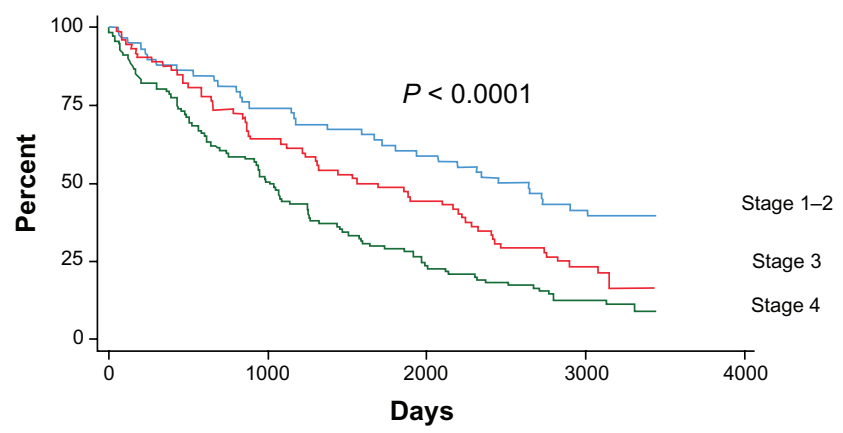

Figure 2 Kaplan-Meier survival curve in COPD patietns according to GOLD stage. Abbreviations: COPD, chronic obstructive pulmonary disease; GOLD, Global Initiative for Chronic Obstructive Pulmonary Disease. mortality of $44 \%$ and severe COPD in $71 \%{ }^{23}$ A study that examined the predictive role of frailty on long-term mortality (12 years) in elderly subjects with and without COPD found that mortality was $48.1 \%$ in non-COPD patients and $60.7 \%$ in COPD patients. ${ }^{24}$ Overall studies on hospitalized patients with AECOPD show higher long-term mortality than population studies, which probably reflect differences in disease characteristics between the groups of patients studied. One of these characteristics may be susceptibility to exacerbations. ${ }^{25}$

The findings of low BMI being a risk factor for mortality in COPD in the present study has been reported before by our group and others. ${ }^{8,18,26}$ In the present study, there was a trend towards a U-shape with the lowest mortality in the overweight and a nonsignificant trend towards higher mortality in the obese group.

The presence of diabetes mellitus is common among patients with COPD. ${ }^{27}$ The findings in the present study of

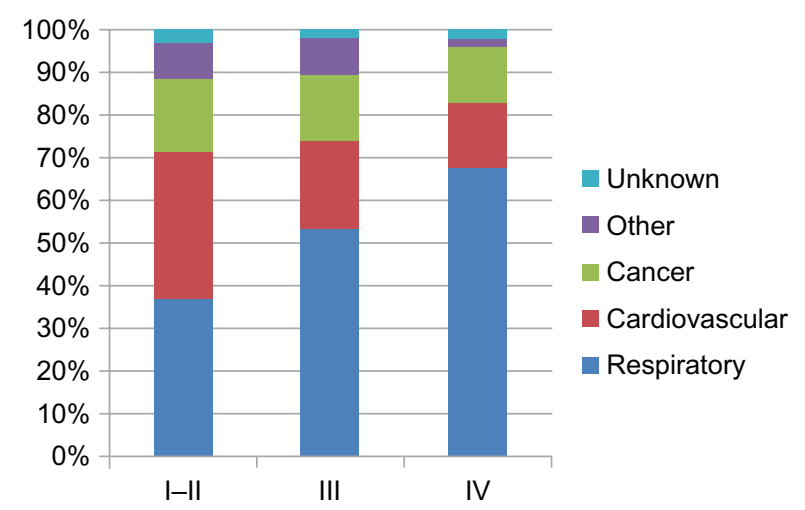

Figure 3 Distribution of causes of death in COPD patients according to GOLD stage. Notes: $P_{\text {respiratory cause of death }}=0.002 ; P_{\text {cardiovascular cause of death }}=0.02$.

Abbreviations: COPD, chronic obstructive pulmonary disease; GOLD, Global Initiative for Chronic Obstructive Pulmonary Disease. 


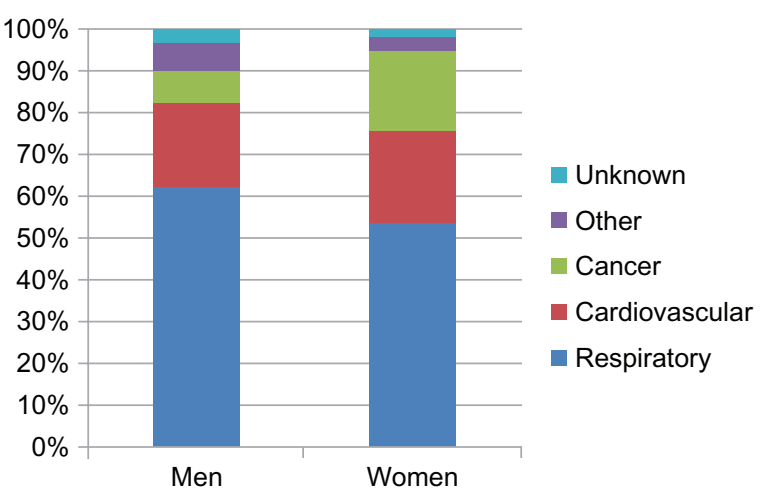

Figure 4 Distribution of cause of death in COPD patient according to sex. Note: $P_{\text {cancer as cause of death }}=0.02$.

Abbreviation: COPD, chronic obstructive pulmonary disease.

diabetes being a risk factor for long-term mortality in COPD confirm our previous findings of short-term mortality. ${ }^{4}$ Mannino et al found that subjects with GOLD stages 3 or 4 COPD had a higher prevalence of diabetes (OR, 1.5; 95\% CI: 1.9-3.0) and higher risk of hospitalization and mortality. ${ }^{28}$ As expected, diabetes in our study was mostly found in COPD patients that were overweight or obese.

The findings of the present study of mortality being related to low $\mathrm{FEV}_{1}$ and higher GOLD stages is comparable to other studies. ${ }^{27,29,30}$

In the present study, most of the patients died from respiratory causes, a result that is similar to other studies. ${ }^{31,32}$ In the large TORCH trial, 35\% died from pulmonary causes, $27 \%$ from cardiovascular causes, and $21 \%$ from cancer. ${ }^{8}$ A study from Italy followed 288 patients for 6 years after hospitalization for COPD and found that cardiovascular diseases were the most common cause of death. ${ }^{18}$ Eleven patients $(5 \%)$ died from lung cancer in our study. It is common for studies to show that a relatively large proportion of the patients with COPD die from lung cancer. ${ }^{8,18}$ This is not surprising given that tobacco smoking is a strong risk factor for lung cancer, but there are also indications that COPD itself is a risk factor for developing lung cancer. ${ }^{33}$ Unfortunately, our study did not have the power to evaluate a possible inverse association between spirometric GOLD stage and death from lung cancer.

There are several strengths of the present study. The study was carried out in three countries with similar health care systems and represents a broad population of patients. It includes a fairly large number of patients, both males and females, and none were lost to follow-up regarding time of death due to the excellent population registration in the Nordic countries. Causes of death are coded in a similar fashion in all the Nordic countries. However, there were also some weaknesses to our approach: As patients had no regular follow up by the study team, the effects of pharmacology interventions, pulmonary rehabilitation and other nonpharmacological interventions being offered to the patients were unknown and all these are also potential factors that may affect the outcome of the patients. However, the study reflects the natural history of COPD subjects being managed under usual care in either the primary or higher level. The multicenter approach results in different database entries. Causes of death were based on death certificates that may not have been accurate and we did not get information on causes of death for all the patients that were included. It has been suggested that relying on the information on death certificates underestimates COPD as the cause of death. ${ }^{34}$ There were also some variables that are thought to be important in patients with COPD that there was no information on in the current study. It has been shown that multidimensional grading systems are better than $\mathrm{FEV}_{1}$ to predict the risk of death. ${ }^{8}$ For instance, we had no information on physical capability and dyspnea that is often a part of such grading systems. This may lead to residual confounding. In evaluating the association between treatment and mortality, it is important to keep in mind that this was an observational study and not a randomized clinical trial.

In conclusion, the present study has clearly demonstrated that long-term mortality in patients after hospitalization with AECOPD was high and that the risk factors for mortality were older age, lower lung function, lower BMI, and diabetes comorbidity. These results should be taken into account when making clinical decisions about patients who have been admitted to hospital with acute exacerbations. Special emphasis should be put on the care of those that have low BMI and overweight COPD patients with diabetes.

\section{Acknowledgments}

The authors wish to thank all the participants in the study. Funding was provided from Boehringer Ingelheim, the Swedish Heart and Lung Association and the Swedish Heart Lung Foundation.

\section{Author contributions}

GG participated in the design of the study and drafted the manuscript. CSU participated in the design of the study, helped with interpretation of the data and helped to draft the manuscript. TG participated in the design of the study and helped to draft the manuscript. EL participated in the design of the study and helped to analyze the data. EB collected data for the study. PB participated in the design of the study, performed statistical analyses and helped to draft the manuscript. 
CJ participated in the design of the study, performed statistical analyses and helped to draft the manuscript. All authors read and approved the final manuscript.

\section{Disclosure}

The authors report no conflicts of interest in this work.

\section{References}

1. Global Strategy for the Diagnosis, Management and Prevention of COPD, Global Initiative for Chronic Obstructive Lung Disease (GOLD). 2011. Available from: http://www.goldcopd.org/. Accessed March 17, 2012

2. Almagro P, Calbo E, Ochoa de Echaguen A, et al. Mortality after hospitalization for COPD. Chest. 2002;121:1441-1448.

3. Connors AF, Dawson NV, Thomas C, et al. Outcomes following acute exacerbation of severe chronic obstructive disease. Am J Respir Crit Care Med. 1996;154:959-967.

4. Gudmundsson G, Gislason T, Janson C, et al. Mortality in COPD patients discharged from hospital: the role of treatment and co-morbidities. Respir Res. 2006;7:109.

5. Tsimogianni AM, Papiris SA, Stathopoulos GT, Manali ED, Roussos C, Kotanidou AJ. Predictors of outcome after exacerbation of chronic obstructive pulmonary disease. Gen Intern Med. 2009;24:1043-1048.

6. Gunen H, Hacievliyagil SS, Kosar F, et al. Factors affecting survival of hospitalised patients with COPD. Eur Respir J. 2005;26:234-241.

7. Fruchter O, Yialga M. Cardiac-troponin-I predicts long-term mortality in chronic obstructive pulmonary disease. COPD. 2009;6:155-161.

8. Calverley PMA, Anderson JA, Celli B, for the TORCH investigators. Salmeterol and fluticasone propionate and survival in chronic obstructive pulmonary disease. $N$ Engl J Med. 2007;356:775-789.

9. Ai-Ping C, Lee KH, Lim TK. In-hospital and 5-year mortality of patients treated in the ICU for acute exacerbation of COPD. A retrospective study. Chest. 2005;128:518-524.

10. Steinmetz J, Rasmussen LS, Nielsen SL. Long-term prognosis for patients with COPD treated in the prehospital setting. Is it influenced by hospital admission? Chest. 2006;130:676-680.

11. Groenewegen KH, Schols AM, Wouters EFM. Mortality and mortalityrelated factors after hospitalization for acute exacerbation of COPD. Chest. 2003;124:459-467.

12. SolerCataluña JJ, MartínezGarcía MA, Román Sánchez P, Salcedo E, Navarro M, Ochando R. Severe acute exacerbations and mortality in patients with chronic obstructive pulmonary disease. Thorax. 2005;60: 925-931.

13. Gudmundsson G, Gislason T, Janson C, et al. Depression, anxiety and health status after hospitalisation for COPD: A multicentre study in the Nordic countries. Respir Med. 2006;100:87-93.

14. Gudmundsson G, Gislason T, Janson C, et al. Risk factors for rehospitalization in COPD: Health status, anxiety and depression. Eur Respir J. 2005;26:414-419.

15. European Community for Coal and Steel. Standardisation of lung function tests. Clin Respir Phys. 1983;19(Suppl 5):22-27.

16. Jones PW, Quirk FH, Baveystock CM, Littlejohns P. A self-complete measure of health status for chronic airflow limitation. The St George's Respiratory Questionnaire. Am Rev Respir Dis. 1992;145:1321-1327.

International Journal of COPD

\section{Publish your work in this journal}

The International Journal of COPD is an international, peer-reviewed journal of therapeutics and pharmacology focusing on concise rapid reporting of clinical studies and reviews in COPD. Special focus is given to the pathophysiological processes underlying the disease, intervention programs, patient focused education, and self management protocols.
17. Zigmond AS, Snaith RP. The hospital anxiety and depression scale. Acta Psychiatr Scand. 1983;67:361-370.

18. Terzano C, Conti V, Di Stefano F, et al. Comorbidity, hospitalization and mortality in COPD: Result from a Longitudinal Study. Lung. 2010; 128:321-329.

19. Steinmetz J, Rasmussen LS, Nielsen SL. Long-term prognosis for patients with COPD treated in the prehospital setting. Is it influenced by hospital admission? Chest. 2006;130:676-680.

20. Garcia-Aymerich J, Serra Pons I, Mannino DM, Maas AK, Miller DP, Davis KJ. Lung function impairment, COPD hospitalisations and subsequent mortality. Thorax. 2011;66:585-590.

21. Nishimura K, Izumi T, Tsukino M, Oga T. Dyspnea is a better predictor of 5-year survival than airway obstruction in patients with COPD. Chest. 2002;121:1434-1440.

22. Lundback B, Eriksson B, Lindberg A, et al. A 20-year follow-up of a population study-based COPD cohort- report from the obstructive lung disease in Northern Sweden studies. COPD. 2009;6:263-271.

23. Mannino DM, Buist AS, Petty TL, Enright PL, Redd SC. Lung function and mortality in the United States: data from the First National Health and Nutrition Examination Survey follow up study. Thorax. 2003;58: 388-393.

24. Galizia G, Cacciatore F, Testa G, et al. Role of clinical frailty on longterm mortality of elderly subjects with and without chronic obstructive pulmonary disease. Aging Clin Exp Res. 2011;23:118-125.

25. Hurst JR, Vestbo J, Anzueto A, et al; Evaluation of COPD Longitudinally to Identify Predictive Surrogate Endpoints (ECLIPSE) Investigators. Susceptibility to exacerbation in chronic obstructive pulmonary disease. N Engl J Med. 2010;363:1128-1138.

26. Hallin R, Gudmundsson G, Suppli Ulrik C, et al. Nutritional status and long-term mortality in hospitalised patients with chronic obstructive pulmonary disease (COPD). Resp Med. 2007;101:1954-1960.

27. Mannino DM, Doherty DE, Buist SA. Global Initiative on Obstructive Lung Disease (GOLD) classification of lung disease and mortality: findings from the Atherosclerosis Risk in Communities (ARIC) study. Resp Med. 2006;100:115-122.

28. Mannino DM, Thorn D, Swensen A, Holguin F. Prevalence and outcomes of diabetes, hypertension and cardiovascular disease in COPD, Eur Respir J. 2008;32:962-969.

29. Schols AM, Slangen J, Volovics L, Wouters EF. Weight loss is a reversible factor in the prognosis of chronic obstructive pulmonary disease. Am J Respir Crit Care Med. 1998;157:1791-1797.

30. Landbo C, Prescott E, Lange P, Vestbo J, Almdal TP. Prognostic value of nutritional depletion in chronic obstructive pulmonary disease. $\mathrm{Am}$ J Respir Crit Care Med. 1999;160:1856-1861.

31. Zielinski J, McNee W, Wedzicha JA, et al. Causes of death in patients with COPD and chronic respiratory failure. Mon Arch Chest Dis. 1997; 52:43-47.

32. Yohannes AM, Baldwin RC, Connolly M. Mortality predictors in disabling chronic obstructive pulmonary disease in old age. Age Ageing. 2002;31:137-140.

33. Turner MC, Chen Y, Krewaki D, Calle EE, Thun MJ. Chronic obstructive pulmonary disease is associated with lung cancer mortality in a prospective study of never smokers. Am J Respir Crit Care Med. 2007;176:285-290.

34. Hansell AL, Walk JA, Soriano JB. What do chronic obstructive pulmonary disease patients die from? A multiple cause coding analysis. Eur Respire J. 2003;22:809-814.

\section{Dovepress}

This journal is indexed on PubMed Central, MedLine and CAS. The manuscript management system is completely online and includes a very quick and fair peer-review system, which is all easy to use. Visit $\mathrm{http}: / / \mathrm{www}$.dovepress.com/testimonials.php to read real quotes from published authors. 